\title{
Salient Trends in Organic Standards: Opportunities and Challenges for Developing Countries
}

\section{Daniele Giovannucci}

Prepared for the World Bank/USAID

Trade and Standards E-learning Course, Jan-March, 2006 


\section{Table of Contents}

Abstract

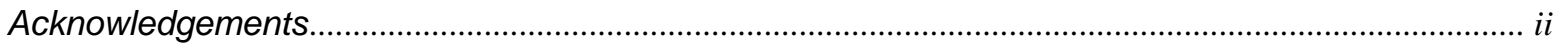

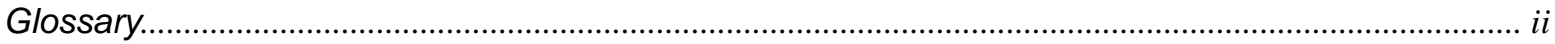

1. THE SCOPE AND ROLES OF ORGANICS IN DEVELOPING COUNTRIES .......................................1

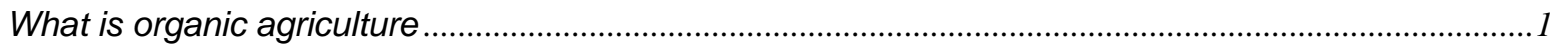

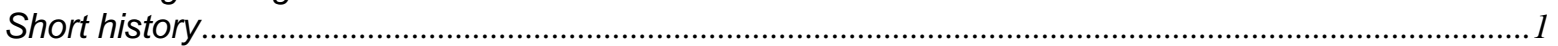

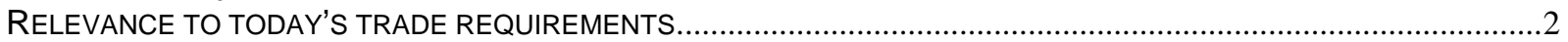

Process Orientation and General Aspects of Organic Certification .....................................................2

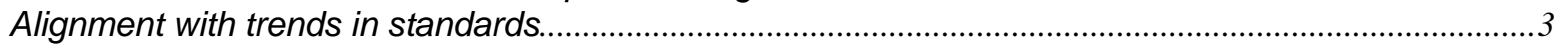

ECONOMIC, SOCIAL, AND ENVIRONMENTAL IMPACTS ...............................................................................

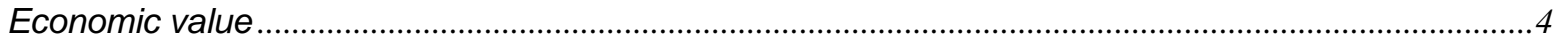

Public Environmental benefits .............................................................................................................6

Community benefits and risk management ........................................................................................

Food \& nutrition security ......................................................................................................................

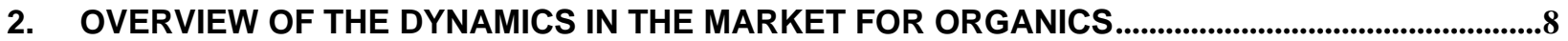

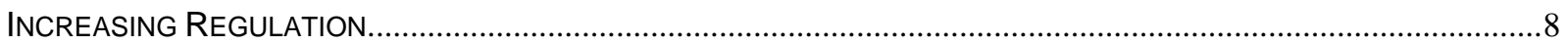

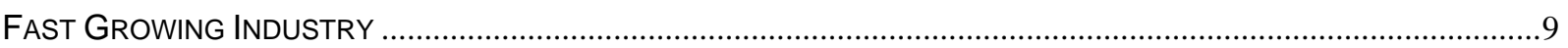

3. THE STRUCTURE \& IMPORTANT FEATURES OF THE INSTITUTIONAL ENVIRONMENT ............11

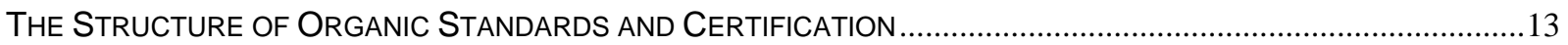

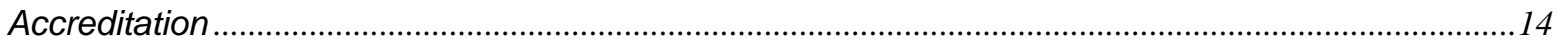

Verification and Certification ..............................................................................................................15

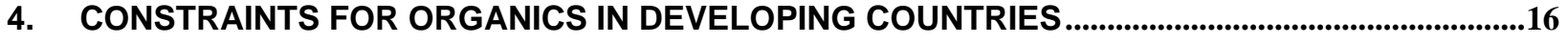

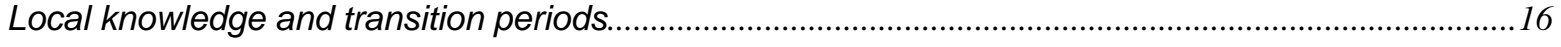

Institutions and incentives.....................................................................................................................17

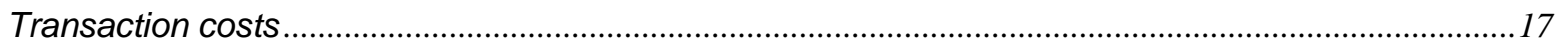

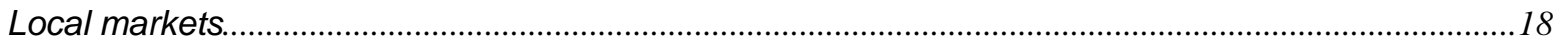

5. KEY POLICY \& INVESTMENT ISSUES AND RECOMMENDATIONS.............................................19

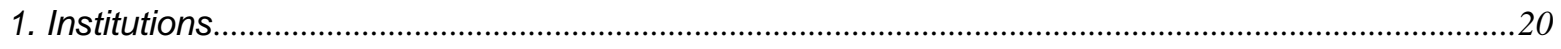

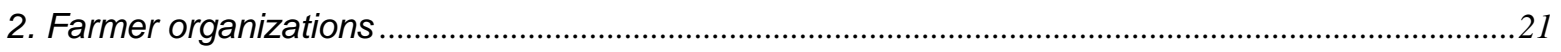

3. Public-private alliances \& small farmers..............................................................................................21

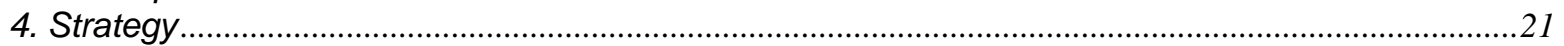

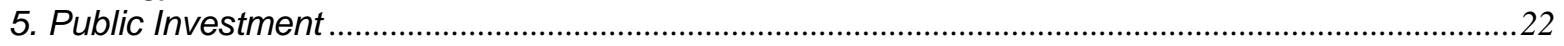

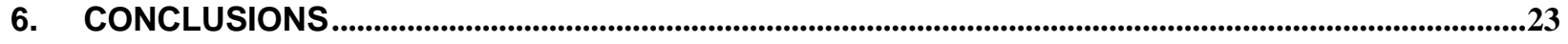

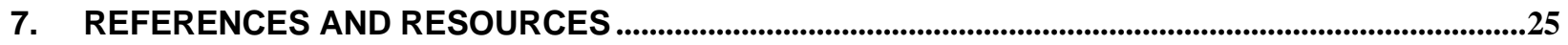

\section{List of Tables}

Table 1. Growth Rates of Organic Markets for Selected Nations ......................................10

Table 2. Comparison of Conventional and Organic: Key Differences................................12

Table 3. Farmer Ranking of Intervention Priorities to Facilitate Conversion.........................20 


\begin{abstract}
This paper presents an overview of the fundamental issues in the production, trade and regulation of organic products. It notes the changing consumer and trade environments that are driving organics beyond the realm of niche products toward an increasingly relevant position among other important agricultural standards. Rather than a comprehensive analysis it outlines key elements that are most relevant to developing country producers including the likely impacts of adopting organics and the salient trends drawing from recent empirical research and the current literature on the subject. Finally, this document briefly assesses the significant constraints and opportunities facing the sector in order to draw some practical policy and investment conclusions.
\end{abstract}

\title{
Acknowledgements
}

Gunnar Rundgren, Steven Jaffee, Helga Willer, Angela Caudle, and Diane Bowen offered useful comments on earlier drafts.

\section{Glossary}

EUREP-GAP European Retailers Produce Working Group Good Agricultural Practice standard

ICS Internal Control Systems

IFAD United Nations’ International Fund for Agricultural Development

IFOAM International Federation of Organic Agriculture Movements

ISO International Standards Organization

IUCN World Conservation Union

FAO Food and Agriculture Organization of the United Nations

GMO Genetically Modified Organism

IOAS International Organic Accreditation Service

JAS Japanese Agricultural Standard

MRL Maximum Residue Levels

NOP National Organic Program of the United States of America

PGS Participatory Guarantee Systems

REACH Registration Evaluation and Authorization of Chemicals (EU draft regulation)

SPS Sanitary and Phytosanitary

Teikei Japanese community-supported agriculture directly linking consumers to farmers

UNCTAD United Nations Conference on Trade and Development

USDA United States Department of Agriculture

WTO World Trade Organization 


\section{The scope and roles of Organics in developing countries}

\section{What is organic agriculture}

There is no single definition for organic farming. Some consider that farming without synthetic inputs is de facto organic but inputs are only one aspect of an organic system. Organic can be defined in a number of ways that alternately capture the regulatory, agronomic, or holistic aspects. Yet two definitions from the literature stand out for their inclusiveness and explanatory faculty.

1. The term 'organic' is best thought of as referring not to the type of inputs used, but to the concept of the farm as an organism, in which all the components - the soil minerals, organic matter, microorganisms, insects, plants, animals and humans - interact to create a coherent, self-regulating and stable whole. Reliance on external inputs, whether chemical or organic, is reduced as far as possible. (Lampkin et al. 1999).

2. Organic agriculture promotes the environmentally, socially and economically sound production of food and fibers. Utilizing both traditional and scientific knowledge, organic agriculture relies on the management of ecological systems and cycles using agronomic, biological, and mechanical methods, rather than external agricultural inputs or synthetic materials. Organic systems exclude the use of synthetic inputs, such as synthetic fertilizers and pesticides, many veterinary drugs, genetically modified seeds and breeds, preservatives, additives and irradiation. By respecting the natural capacity of plants, animals and the landscape, they aim to optimize quality and sustainability in all aspects of agriculture and the environment. Organic agriculture adheres to globally accepted principles, which are implemented within local social-economic, climatic, and cultural settings. (adapted from various IFOAM publications).

While a single definition is important in terms of achieving harmonized standards to facilitate international trade and consumer acceptance, organics -- by their very definition - must also lend themselves to the inherent variations of a particular place and its conditions.

\section{Short history}

Today, organics are one of the fastest growing segments of the agro-food industry that are increasingly drawing the attention of producers, governments and development agencies for their potential capacity to improve the livelihoods and conditions of farmers - particularly small ones. The certified retail sales in 2005 are valued at about US \$28 billion with non-certified sales increasing this figure considerably. While organic methods have been around for millennia, it is only in the last century that they were coherently conveyed in organized guidelines for agricultural production. ${ }^{1}$ In fact, organics go well beyond standards to encompass a bio-systemic approach to rural development and, for many, represent a harmonious existence within one's environment.

\footnotetext{
${ }^{1}$ The standards eventually also applied to storage, processing, transport, and marketing.
} 
Their popularity has increased dramatically as an alternative to the perceived shortcomings of conventional methods in the last 2-3 decades and this popularity has exploded within the last 10 years as a result of a considerable upswing in consumer interest and increased government support in key nations (i.e. EU subsidies and US Cost Share Program). The market interest has resulted in organics emerging from an obscure niche in limited retail distribution channels such as health food stores and farmers' markets to become available in even the largest global food retailers such as Carrefour, Wal-Mart, and Ahold.

Systemic approaches to organic agriculture emerged in different parts of the world from the 1920 s to the 1940s. Organic methods were disseminated primarily within the context of the ideologies and writings of four prominent $20^{\text {th }}$ century icons. After the early ravages of the industrial age, Rudolf Steiner, Albert Howard, Robert Rodale, and Eve Balfour drew attention to the biological basis of soil fertility and its links with animal and human health. By the 1950s and 1960s most farmers that called themselves organic espoused one or more of these ideological approaches. In most cases they operated within systems of local trust where there were few formal guidelines.

The International Federation of Organic Agriculture Movements (IFOAM), originally based in Switzerland, came into being in 1972 to provide a common international platform for discussion, policy, and experimentation as well as to begin coordinating the many somewhat disparate approaches that had evolved. Most of the private organic associations and organizations that had emerged in different countries developed their own codes or standards. Meeting these standards entitled members to use the respective associations’ organic labels. By the mid-1970s as markets for organic products expanded away from more localized and trust-based systems, on-site inspection began to be a common part of organic systems in order to verify that farmers complied with standards. In the U.S., the states of Oregon and California pioneered legal regulations of organics. Soon thereafter, by the early 1980s, independent third party certification organizations emerged to conduct inspections. As the sector grew in many countries it also attracted national government regulation starting with France in 1985 and expanding within Europe in the 1990s before spreading to other national markets, particularly the U.S. In addition to the US and the $25 \mathrm{EU}$ countries with regulations by 2005, about 18 other countries had implemented national organic regulations (43 total) and about twenty-eight others are currently in the process of either implementation or drafting (Kilcher et al. 2006).

Relevance to today's trade requirements

\section{Process Orientation and General Aspects of Organic Certification}

For products to be labeled "organic" requires them to have been produced according to specifically defined organic methods or processes and to have utilized only permitted inputs. Organic is therefore a process standard and not just a characterization of the final product. Having clearly defined input, production, and processing standards along with procedures to certify these are among the essential elements distinguishing organics from most other forms of agriculture. 
Organic certification covers several important areas of agriculture and more recently of aquaculture as well ${ }^{2}$. There are preliminary conversion requirements that help to ensure that the cultivation medium and the area are reasonably free of contaminants or synthetic agrochemicals. Then certification addresses the processes of cultivation, particularly issues of fertilization, crop protection, and risks of contamination. For animal husbandry, certification typically covers animal nutrition, growing conditions, veterinary care, and slaughter. Throughout all phases of organic processing and handling, there is thorough traceability of the product. There are also rules for transport, segregation, cleaning/disinfecting, and packaging.

Issues of social justice (i.e. labor rights and conditions) are also part of organic principles but are only rarely part of certification requirements ${ }^{3}$. Similarly, biodiversity principles are clearly embedded in organic principles but are rarely specifically applied or enforced in certification processes. Labeling requirements are relatively straightforward for most countries and protect the use of the term "organic" and related words like "bio". Labeling rules typically follow official national regulations.

As market-oriented standards, organics very much follow the trend of other leading private standards that increasingly define the parameters and the conduct of trade. As noted in Giovannucci \& Reardon (1999) standards have shifted from being neutral market lubricants to becoming tools for product differentiation. This implies a fundamental shift in their role from reducing transaction costs to new roles as strategic tools for market penetration, quality and safety assurance, and product niche definition.

\section{Alignment with trends in standards}

Organics standards certification provides a useful understanding and application of some of the agricultural requirements necessary today for producers to compete in high-value or global supply chains. Organic standards can be a gateway to higher value trade. For example: detailed recordkeeping of production inputs; field to table traceability; absence of agro-chemical residues; and third party monitoring that are part of organics are also essential aspects of many of the advanced standards necessary to effectively participate in agricultural trade with more lucrative developed markets. Participants in the organic industry may even have an advantage at least for a while- over many producers of commodities or undifferentiated products because of the potential for increased technical and commercial learning within the more face-to-face nature of some organic supply chains. These can permit organic producers to better understand the requirements and trends of target markets.

Increasingly, sustainability concerns are emerging in many private standards such as EUREPGAP and ISO. Part of the popularity of organics stems from the ability of suppliers to meet several different types of concerns. Environmentally, organics are recognized as one of the most

\footnotetext{
${ }^{2}$ Aquaculture, particularly of shrimp, is the subject of considerable debate in organic circles. In the US, NOP still does not regulate it so standards are private. In the EU, aquaculture is part of the scope of regulation, but the detailed rules are missing. Japan does not yet regulate it.

${ }^{3}$ IFOAM basic standards have a social chapter and the UK's Soil Association, KRAV, and a few others also have social requirements.
} 
conservation-oriented approaches to agriculture. At the level of human health, the field to table traceability, animal management requirements, and restrictions on the use of agrochemicals provide reasonable assurances of increased farmer safety, food safety, and - according to a number of recent nutrition studies - improved food quality. Social concerns, although addressed as principles are not explicitly defined except in IFOAM's basic standards and some private standards. Economic concerns have long been a part of organic systems particularly in the aspects concerning farm level diversification and fair remuneration or a price premium for the processes and certification undertaken.

\section{Economic, Social, and Environmental Impacts}

For many countries, especially more populous ones, - where key resources such as the arable land and water necessary for agriculture are diminishing on a per capita basis - more productive agricultural methods will be important, and the existing land and water resources must be utilized prudently. Thus, any form of agriculture, organic or otherwise, should be assessed in relation to the following ${ }^{4}$ :

1. Economic impact on productivity, profitability, and income security

2. Impact on the ecological foundations of productivity such as soil health, water quantity and quality, biodiversity, and personal health

3. Food and nutrition security

\section{Economic value}

Worldwide, about 31.4 million hectares have been certified for organic agriculture in 2005; if wild harvest areas are also included then the certified organic area reaches 51.1 million hectares according to an upcoming IFOAM report (Willer \& Yussefi 2006). The non-certified acreage used for local or household consumption would double the total land area being farmed according to organic principles. A number of European countries have seen considerable increases over the last decade or so. More than 11\% of Switzerland's and about $14 \%$ of Austria's farmland is organic according to statistics reported by Willer \& Yussefi (2006). Sweden will soon pass $20 \%$ managed organically with about $7 \%$ certified.

A number of developing countries are showing significant rates of adoption despite the absence of formal government support or incentives. Private enterprise and in some cases NGOs typically stimulate adoption. ${ }^{5}$ In Uganda there are now about 35,000 certified organic farmers ${ }^{6}$ and in Mexico, nearly 120,000 small farmers produce certified organic coffee, cacao, fruit, vegetables, spices, and staple foods. Brazil, according to its Minister of Agriculture ${ }^{7}$, is on its way to a $20 \%$

\footnotetext{
${ }^{4}$ Based on ideas emerging from discussion with M.S. Swaminathan Oct 2004

${ }^{5}$ They often also control ownership of the organic certificates.

${ }^{6}$ Rundgren personal communication from EPOPA program Jan 11, 2006.

${ }^{7}$ Presentation made at BioFach America Latina November 2005
} 
share of organics in total production from today's 3\% that was achieved in just a few short years. China’s organic exports reached an estimated US \$200 million in 2005 (Giovannucci 2005a).

At the farm level, the economics are less straightforward. The evaluations of smaller farmers conducted in Asia and Latin America for The International Fund for Agricultural Development (IFAD) suggest that it can be misleading to compare organic costs after conversion with previous costs because a significant portion of the new costs result from process changes in quality control and harvesting that can be considered as new investments in order to meet the standards of a new and higher paying market. Furthermore, measuring total farm yields is more appropriate than measuring single crops since planting multiple crops and diversification away from dependence on a single cash crop is a characteristic of organic farming as are multi-year crop rotations that can alter the economic equations.

Nevertheless, when measuring just single cash crops a shift to organic farming from a traditional or rustic form of cultivation tends to increase labor costs but has positive consequences in terms of both yields and profitability due primarily to better management practices and price premiums. For such traditional producers, organic systems usually provide better incomes, particularly if they can access organic markets. The same is typically true for farmers in rain-fed areas. However, switching from intensive forms of agriculture to organic farming may reduce input costs, will increase labor costs, and will probably reduce yields at least initially, while overall income is higher due mostly to the current levels of price premiums.

For intensive conventional producers, the first-year yield reductions are often considerable and most do not earn premiums during this transition (conversion) period for their crops. By the third year, yields typically stabilize but often at a somewhat lower level than is achieved with some intensive conventional systems. Caution is therefore warranted in such situations and proper assessment is advised (see section 5 below: Key Policy \& Investment Issues and Recommendations). Nevertheless, for some of the more sophisticated conventional farmers who are able to take full advantage of organic methods (i.e. cotton in India or sugar in Brazil), yields can actually improve. In northern countries, the two longest running and best studied field trials (FiBL Switzerland and Rodale USA) have decades of data demonstrating the relative benefits of organic vs. conventional farming using comparable state-of-the-art applications for both.

With few notable exceptions (i.e. van der Vossen 2004), much of the literature suggests that organic and similar approaches (low external input sustainable agriculture) can provide considerable benefits to farmers and their communities with relatively low direct costs (Pimentel 2005; Damiani 2003; Mader et al. 2002; FAO 2002; Altieri 1999). ${ }^{8}$ There has been little research on the potentially considerable indirect costs such as learning curves and institutional support incurred to adopt organic standards.

\footnotetext{
${ }^{8}$ A 2002 review of dozens of organic projects covering more than a hundred thousand households in a range of developing countries noted patterns of increased crop yields in the vast majority of cases (FAO 2002). The 2005 Pretty et al. review of 286 recent agricultural interventions in 57 poor countries, while not focused exclusively on organics, notes increased productivity on most of the 12.6 million farms covered while also generally improving the supply of critical environmental services.
} 
All of the participants engaged in the value chain for certified organics, not just farmers, earn higher margins than with comparable conventional products. While a varying proportion of the higher retail prices for most organic products do reach farmers, the downstream supply chain generally captures a large share of the higher price and this is only partly reflective of the higher costs of less efficient channels (fewer scale economies, less experience, small market influence) and maintaining segregated and sometimes parallel post-harvest systems as required for certification. Capturing value can be determined by the actual ownership of the certification that is frequently in the name of a company organizing smaller farmers.

For decades, the rapid demand growth outpaced production thereby stimulating high price premiums for many organic products. It is impossible to generalize about premiums since they vary considerably between different products, different markets, and even different times of year. Nevertheless, while premiums for many products are still considerable, there appears to be a general downward trend in premium levels paid to farmers, particularly in highly competitive commodities such as coffee and rice. Hamm, Gronefeld \& Halpin (2002) note that in a number of European countries surveyed the median consumer premiums had declined to a range of $15-40 \%$ by 2002 . In countries such as the UK where supermarkets dominate the organic retail trade, prices tend to be lower, about $20 \%$ lower than the EU average in this case. The highly competitive US market seems to also be experiencing a decline in premium levels for some products.

\section{Public Environmental benefits}

Organic precepts dictate working in harmony with the biodiversity of the farm and the surrounding areas (Scialabba, Grandi, and Henatsch 2002) and this coincides with the findings of a review of 33 published studies on the biodiversity differences between organic and conventional farming systems (Bartram and Perkins 2003).

As arable land declines due to degradation and erosion, its quality becomes increasingly important. Organics are one of the few agricultural methods that actively address important issues of erosion, degradation, and desertification and are particularly suitable for application in marginal areas

. Organic methods are well-documented to improve soil quality, tilth, and stability, and improve its moisture absorption and retention properties (FAO 2002; Mader et al. 2002; Reganold et al. 2001; Drinkwater, Wagoner, and Sarrantonio 1998). Healthy soils can therefore better withstand drought and torrential rain (Lotter, Seidel and Liebhardt, 2003). Soil stability reduces both water and wind erosion as does the organic practice of interplanting different species. Therefore, organics can not only preserve valuable soils but can also serve to remediate distressed areas while simultaneously providing an economic return.

The rural poor in many parts of the world depend on common-property resources that face particularly heavy pressure and degradation (IFAD 2002). Organic farming communities in China and India noted that organic principles help them to better understand their environment and as a consequence, there has been less pressure on local forest resources, an increase in the planting and conservation of useful species, and reduced or at least better-terraced hillside farming (Giovannucci 2005a). 
In some cases, the higher prices received for organic crops provide a better livelihood and when linked to certification can serve to support conservation by diminishing the need to expand the agricultural frontier in order to survive. Since organic methods contribute to the long-term fertility of soil there may be less incentive for shifting cultivation and slash and burn methods. Even from the government's fiscal point of view, organic agriculture can be a valuable and lowcost asset. For example, China's Environmental Protection Agency is considering offering organic agricultural incentives in some areas for the remediation of pollution at the watershed level. Organic agriculture bundles both a product and an environmental service, and when organic products are sold at a premium, they effectively pay for farmers to conserve natural resources and biodiversity.

\section{Community benefits and risk management}

Organic agriculture tends to involve rural communities in environmental protection, resource management, and knowledge dissemination. The increased demand for labor that is characteristic of organic methods can contribute to rural stability especially where the labor force is underemployed. However, it should be noted that conversion to organics could be problematic where labor is scarce, particularly in the context of the increasing feminization of agriculture. Organic agriculture can also contribute to new small enterprise development where value is created locally with biopesticides, vermicomposting and other inputs. Because organic agriculture tends to value local approaches that have usually evolved as sustainable responses to local needs and the wisdom of elders who have long experience with nature's cycles, it can help to sustain local culture. Realizing the potential for such broad socio-economic benefits, state and local governments in India, China, and a handful of other countries have recently taken active steps to help facilitate organic conversion.

\section{Food \& nutrition security}

Because organic agriculture can involve a significant shift in production methods, it sometimes raises concerns for potentially reduced yields and the impact on food security. It is well known that food security is as much related to access as it is to actual production of food. About $80 \%$ of all malnourished children live in countries that enjoy a surplus of food production (Worldwatch Institute 2000). Food security is of particular concern in areas of poverty where marketing, storage, and distribution systems are inadequate. This is the case in remote rural areas where many of the world's poorest live and where food shortages and malnutrition can easily result from local crop failures.

The IFAD evaluation of organics in Asia (Giovannucci 2005a) points out that organic agriculture can directly address this issue in a number of ways. By fostering agricultural methods that improve not only the natural fertility of the soil but also its stability to withstand natural calamities such as drought (Altieri 1999; Drinkwater, Wagoner, and Sarrantonio 1998), and more efficiently use nutrients (Mäder et al. 2002), the likelihood of food shortages can be reduced. Since organic farmers rely on their management of local resources rather than on external inputs or food distribution systems over which they have little control or access, they can improve local food security. 
Organic farms typically grow a variety of crops and livestock in order to optimize species interaction and nutrient use. Such diversification intrinsically reduces the likelihood of catastrophic crop failure. This is particularly true in rain-fed systems where such resilience is a critical factor in difficult years. Farm diversity not only reduces risk, it also contributes to having food available at different times of year and also having a greater range of nutrients than would be expected from the monocrop or few crop systems that are typical of conventional approaches. Farm management characteristics such as diversification are by no means exclusive to organics; they can be adopted to varying extents by most farmers.

\title{
2. Overview of the dynamics in the market for organics
}

\author{
Increasing Regulation
}

With the reduction of formal trade barriers i.e. tariffs \& quotas, the applications of technical or sanitary and phytosanitary (SPS) measures have an increasingly important influence on the volume and direction of international agricultural trade. SPS measures are intended to ensure human food safety, protect agricultural plant and animal populations and ecosystems. The WTO Agreement on the Application of Sanitary and Phytosanitary Measures (SPS Agreement) recognizes that each country has the right to establish the levels of protection of human, plant, animal, and environmental health and safety that it considers to be appropriate for imports, provided that the measures it uses to achieve such protection are based on science and risk assessment. Such measures, often in the form of standards and regulations, are increasing considerably. Environmental and related health requirements (ERHRs) - provisions for which are contained in both the SPS agreement and the WTO Agreement on Technical Barriers to Trade (TBT) - have taken on an increasing importance. There are indications of considerable growth in the share of such notifications to the WTO rising from $10 \%$ in the early 1990 s to $18 \%$ a decade later (UNCTAD 2006 pp 5-6). The US Bioterrorism Act and the EU's chemical safety (REACH) rules signal a clear trend toward increasing governmental regulation of agricultural products.

Private firms are also increasingly demanding that the food and agricultural products that they source meet ever more stringent requirements. Most private standards exceed the requirements set by governments. This means there will be an escalating need to meet technical specifications and have internationally credible certification to appropriate standards. Organics intrinsically provide some of these requirements.

Food safety concerns and loss of faith in public regulations have been a prime impetus for organic development in a number of countries as distinct as China and the UK. For example, the increasing growth of demand for livestock products in most nations - including developing countries - has increased trade of factory-farmed products that are causing considerable consternation and consumer fear as their potential dangers become increasingly evident. ${ }^{9}$ It is not

\footnotetext{
${ }^{9}$ For example one of the world's most prominent medical associations warned of the dire human health consequences of the increasing resistance to antibiotics in the U.S. where only $12 \%$ of all antibiotics are used for humans and the remaining $88 \%$ are routinely fed in intensive livestock operations (New England Journal of
} 
just consumers or trading nations that care, according to industry news, McDonald's, one the world's most notable retail brands wants the eggs they serve to be laid by hens with more square inches of living space. Similar concerns are arising in the multi-billion dollar aquaculture industry. The standards under which organic livestock and aquaculture products are produced make them more immune to these sorts of problems. In fact, the organic livestock sector tends to experience considerable sales increases as food safety issues flare up in the news. While organic aquaculture is relatively new, the large scale production and trade of organic livestock is already well developed in countries as diverse as Australia and Argentina. Given the increasing health concerns surrounding conventional production methods, organic products could present a useful opportunity in the near future.

\section{Fast Growing Industry}

Certified organic products are produced in 130 countries in commercial quantities, including more than 90 developing countries (Kortbech-Olesen, 2000) and IFOAM's members span 110 countries. Until recently, expansion of organic markets had occurred mostly within a core audience of believers and through small and less demanding channels of distribution and sales.

Organic products are successfully transitioning to a more mainstream consumer base and corresponding mass-market channels. Multinational distribution and retail giants are adopting higher sourcing standards as part of their escalating need to differentiate themselves and also to manage their exposure to food contamination risks and reputation risks (i.e. child labor, pesticide residues, GMOs). Leading corporations such as McDonalds, Nestle, Heinz and Unilever have already launched some organic products. In such new distribution channels, organic producers will have to compete on costs, promotion, and efficient supply chains. In most cases they will have to meet the same competitive parameters as their conventional counterparts but their intrinsic fulfillment of important standards i.e. traceability and residue levels may provide a distinct advantage.

In many developed countries, organics have emerged from small niche markets to enter the mainstream distribution channels rather quickly. For example, in 1995, specialty natural products retailers in the U.S. sold two-thirds of all organic food but by 2003 their share shrank to 47\% while conventional supermarkets garnered a $44 \%$ share of all organic food. In Japan $62 \%$ of certified organics are sold through supermarkets according to the Agriculture Promotion Foundation. These developments present considerable opportunities for the increased visibility and growth of the sector.

The US market, now the largest, is expected to double at current growth rates in the next sixeight years, according to the Organic Trade Association. In some emerging markets, optimism about high rates ought to be tempered by their small market sizes. The table below notes some recent estimated market growth rates for the regions that together represent about $95 \%$ of total certified organic sales.

Medicine, 1999). That Journal has also noted that a likely result is that antibiotic resistant infections had increased 800\% between 1992-97. Some countries have banned the routine prophylactic use on livestock and Denmark, for example, saw its antibiotic resistance drop from 82\% to 12\% (Robbins, 2003 p.141) 
Table 1.

Retail Growth Rates of Organic Markets for Selected Nations (2003-05 average estimates)

\begin{tabular}{l|c|}
\multicolumn{1}{|c|}{ Region } & $\%$ annually \\
\hline USA - Canada & $16-20$ \\
\hline $\begin{array}{l}\text { Europe's Mature Markets } \\
\text { (Germany, Netherlands, Switzerland) }\end{array}$ & $5-8$ \\
\hline $\begin{array}{l}\text { Europe's Emerging Markets } \\
\text { (Spain, Greece, Czech Republic, Hungary, Slovakia) }\end{array}$ & $15-20$ \\
\hline AVERAGE & $10-15$ \\
\hline
\end{tabular}

Source: Author estimations drawn from OTA, Organic Monitor, Organic Standard, and IFOAM.

Growth, however, is certainly not uniform in any nation and certain segments are far more successful than others. For example, nearly 30\% of Denmark's milk is certified organic while less than 2\% is organic in France. In the US, processed foods have grown exponentially in the last decade while basic grains grew at less than 5\%. In Germany, the baby food sector is almost entirely organic with an $80 \%-90 \%$ market share but organic coffee had only about 1-2\% of the market. Egypt's best-selling packaged tea is organic but the range of processed organic products is still very small.

While the food industry overall is growing at approximately 1-2\%, global organic sales have achieved double-digit annual growth for more than a decade and now have a worldwide estimated retail value of approximately US\$ $28-30$ billion in $2005^{10}$. The US market is the largest with about US $\$ 13$ billion in 2005 sales while the Western European countries have a joint market approaching US \$14 billion (Sahota 2006). The other major markets, including Japan, register about US \$1 billion in sales. Historically, most certified organic sales have occurred in a select group of wealthier countries. Nearly all of the certified organic production from developing countries is exported. According to Sahota's estimates, certified sales still occur mostly in Europe and in North America with shares of $48 \%$ and $46 \%$ respectively ${ }^{11}$.

\footnotetext{
${ }^{10}$ Organic products are not separately classified by any of the major statistical classifications i.e. the Harmonized Commodity Description and Coding System, Standard International Trade Classification (SITC), International Standard Industrial Classification of All Economic Activities (ISIC) and few governments track them separately so there are very few reliable trade statistics on organic products. The FAO has made efforts in this area and consortium of institutions is attempting to develop a European Information System for Organic Markets. Efforts by IFOAM are based on estimations of experts yet they currently offer the most credible global statistics.

${ }^{11}$ This represents a considerable re-stating of the data used in earlier years that included much higher figures for Japan's domestic organic sales. After the implementation of its JAS regulations, many products with an established domestic market elected to continue selling but not pursue official certification to the new organic legal standard and therefore the certified sales had to be adjusted downward although the sale of these products supposedly produced according to organic methods reportedly continue to grow.
} 
This appears to be slowly changing as developing country consumers increasingly grow their organic markets but most of these domestic sales are for products that are not third party certified and sales are difficult to estimate. The escalating globalization of homogenized tastes and concerns especially for nutrition, health, and food safety are likely to further drive the growth of similar markets in developing countries. Small but viable domestic markets are already emerging in places as diverse as Argentina and India or Mexico and China. Just as in the major markets two decades ago, localized transactions within affinity groups in these markets require few certifications and are often conducted on the basis of trust and local assurance.

After only a few years of existence, the certified domestic organic market in China was valued in 2004 at approximately US $\$ 150$ million $^{12}$ retail. The value of exports has expanded from less than US \$1 million in the mid-1990s to US \$142 million in 2003. The potential is notable in China's certified Green Foods (similar to organics) that are already one of the most successful eco-labeling programs in the world. Annual retail sales nearly reached US \$12 billion in 2004; about the size of the US organic market (Giovannucci 2005a). South Korea, India, Thailand, and Indonesia are among those registering growing sales in Asia. Turkey's internal markets have grown along with organic exports that doubled from US \$18 million in 1998 to US \$36 million in 2003. ${ }^{13}$ Argentina, Brazil, Peru, and Costa Rica all have growing markets primarily in larger urban areas. Mexico now has a organic markets in many cities reflecting the strong growth in exports that climbed from US \$34 million in 1996 up to US \$280 million in 2002 (Gómez and Gómez 2004 cited in Twarog 2006). On the African continent only South Africa and Egypt have significant markets. For example, organic products are now becoming available in the Egyptian mainstream channels. The organic (biodynamic) organization SEKEM delivers its products to some 20,000 shops throughout the country.

\section{The structure \& important features of the institutional environment}

Organic farming as a systematized and certifiable approach to agriculture is a relatively new phenomenon. Over the course of decades it had remained mostly in the private realm of a few small scale farmers with specific organic standards set and monitored by private organizations. It is no surprise then that with the rapid proliferation of distinct private standards and government regulation in many countries that the organic sector would face some challenges. The public sector is inexperienced in terms of both understanding and managing the needs of organic farmers and the markets for their products while the private sector also faces the challenges of few sources of support and information along with the increased costs of navigating the diverse requirements of the many private standards and governmental regulations.

Policymakers tend to be polarized in their views of organic farming; they see it either as a very lucrative modern niche that can even be elitist or as a traditional and perhaps backward approach used only by the poorest farmers. This interesting dichotomy reflects the somewhat different

\footnotetext{
${ }^{12}$ There have since been some questions about the Chinese classification of certified and non-certified organic sales that would suggest a somewhat lower figure.

${ }^{13}$ Personal communication with Director of ICEA’s Izmir office in November 2005.
} 
historical and didactic experiences in different countries. Nevertheless, a great many developing countries are recognizing the opportunities and moving forward at the policy level. By 2005 there are about 60 countries that have implemented or are drafting national organic regulations.

Regulations for organics are an increasingly contentious issue. Organic farmers and their crops must, of course, meet all of the regulatory requirements of conventional farming as well as the organic standards. There is little research on the impacts of formal organic regulations, but anecdotal evidence suggests that the tradeoffs involved in such restrictions (i.e. issues of access, costs, bias against the smaller or poor farmers) may sometimes be unnecessary. Therefore, when official organic regulations are imposed on the sector - at least at the early stages of development - they may stifle organic growth and reduce the potential benefits to the poorest.

Although organic systems appear to produce fewer negative externalities than conventional farming in terms of both human and environmental well-being, the regulatory and certification requirements associated with them impose extra burdens. Farmers wishing to convert from conventional approaches toward organics also incur considerable costs (compliance, transition yields, certification) for adopting methods that may likely be more societally beneficent (i.e. resource conservation, pollution, food security). In many countries the dominant agricultural policies and regulations neither encourage nor support organic farming practices. Regulation is not the only distinction however. There are considerable differences in both the institutional and market factors between conventional and organic systems in most countries as Table 1 illustrates.

Table 2.

\section{Comparison of Key Differences Between Conventional and Organic Systems}

\section{Conventional}

1. Large markets

2. Easy market access

3. Modest growth rates

4. Intense competition

5. Rewarded for quality \& low price

6. Gov. support: subsidy, R\&D, extension

7. Capital intensive

8. Short learning curve

9. May face more trade barriers

10. Strong downward price pressures

\section{Organic}

\section{Smaller markets}

2. Less accessible markets

3. Robust growth rates

4. Moderate competition

5. Rewarded for quality \& process

6. Limited government support

7. Knowledge-intensive

8. Longer learning curve

9. Incorporates traceability, MRL, other standards

10. Price premiums in the marketplace 


\section{The Structure of Organic Standards and Certification}

At the international level there are two bodies that determine the direction of organic rules. The International Federation of Organic Agriculture Movements (IFOAM) is a non-profit and nongovernmental organization with UN observer status that represents more than 700 organizations around the world. It has established widely adopted guidelines for organic production and processing and is the nexus of most discussions concerning amendments and changes as well as a resource for nations determining their own national standards. The IFOAM Basic Standards are widely accepted minimum guidelines, leaving room for more detailed requirements, depending on specific local situations.

The Codex Alimentarius Commission as an official inter-governmental body has worked with IFOAM's Basic Standards to formulate international reference guidelines that would serve as the basis for national standards. Codex has adopted IFOAM's work with minor changes and it is similar though not the same on most points. Although it has generated its own "Guidelines for the Production, Processing, Labeling and Marketing of Organically Produced Foods", Codex is much slower to respond to changes as demands and needs evolve, leaving IFOAM as the de facto international standards setting body.

Governments of the largest organic markets -- the US, EU, and Japan -- have elected to regulate organics by statute and this may have led to clearer rules but also to a greater and more diverse set of requirements that can easily act as barriers to entry, particularly for smaller farmers and enterprises. In the EU, for example, a common organic regulation (No. 2092/91) has been implemented in national legislation to regulate the production, processing, transportation, and importation of organic products and to uniformly protect the use of words like organic, ecological, eko, biological, and bio. Nevertheless, the details of organic certifications, their acceptance, and the bodies that are accredited for certification and inspection, still vary from country to country. There are several reasons for mandatory governmental regulations such as consumer protection, clear differentiation for farmers, a 'level playing field' and facilitating the determination of who has the right to receive organic production subsidies that have sometimes been available from governments. Yet it is not clear that these goals have been effectively achieved through the regulations.

Most national regulations - particularly between the two major markets - are not homogenous and while efforts to achieve 'harmonization' between different national regulations are underway, it is unlikely that this issue will be resolved soon. An ongoing process to rationalize these distinct approaches appears to be moving slowly on several fronts. At the multilateral level, through the International Task Force on Harmonization and Equivalence in Organic Agriculture (convened by IFOAM, FAO, and UNCTAD and including governments, private sector bodies and international organizations), harmonization discussions aiming to establish equivalent standards and requirements have labored for several years. The process thus far has generated an analysis of the situation and some consensus as the stakeholders have agreed on directions for further development and are now moving into a more solution-oriented mode. ${ }^{14}$

\footnotetext{
${ }^{14}$ For more info, see: http://r0.unctad.org/trade_env/itf-organic.htm
} 
At the bilateral level the major regulators (EU, US, Japan) have not elected to look at the difficult task of harmonization and engaged instead in bilateral negotiations toward equivalency. The term 'equivalence' denotes that certain standards, though different from each other and therefore not harmonized, nevertheless are acknowledged to fulfill common objectives. There has been some limited progress such as Japan's equivalency agreements with the US and the EU but these are restricted to US \& EU products entering Japan without re-certification. The EU has extended equivalency status to a few other nations but only three developing countries are on the list: Argentina, Australia, Costa Rica, India (expected approval in 2006), Israel, Japan, New Zealand and Switzerland. The US does not recognize any other standards as equivalent.

The main route for organic products to reach the dominant EU and US markets is through direct certification to those standards by an accredited certification body rather than using equivalence agreements. The US has a system whereby a certification body outside the US can apply for direct accreditation by the USDA but it must certify strictly according to the USDA's NOP rules. The EU currently has a system that allows the members states to accept imports on a case-bycase basis for which permits are issued ${ }^{15}$. At the end of December 2005, the European Commission adopted a proposal for some new organic regulations. If accepted this proposal would establish a system for approval of foreign certification bodies by the EU.

\section{Accreditation}

Each individual government that has organic standards nominates a body to approve or accredit ${ }^{16}$ the certifiers that inspect for compliance with a standard and then confer the right to market a product as organic. This ensures that they meet certain minimum requirements since the technical regulations, especially for processed products can vary from country to country ${ }^{17}$. In the private sector, the International Organic Accreditation Service (IOAS) is an independent body that has emerged from IFOAM to provide a measure of consistency and credibility at the international level among certifiers. It can authorize certifiers to use the IFOAM seal if they meet accreditation requirements. Accreditation serves as a basis of trust among accredited certifiers and thereby can facilitate trade between markets where different certifiers are dominant or more accepted. For example, until recently Sweden's dominant certifier only accepted IFOAM accredited certifiers as equivalent for automatic re-certification.

\footnotetext{
${ }^{15}$ Approximately $80 \%$ of imports access the EU market through a mechanism that is a temporary derogation of the regulation.

16 "Accredit" refers to the process of sanction by an accreditation body. "Approve" is any other process for approval other than accreditation. For the technical discussion of this topic, see Rundgren 2005.

${ }^{17}$ Some countries regulations allow processed products to be made with less than $100 \%$ certified ingredients and these have specific content requirements for the percentage of products that can be non-organic or uncertified depending on the category. Labelling regulations are critical factors that determine the progress and direction of organic markets. For example, the US permits four distinct legal uses of an organic term on the label including a "made with organic products" label that can be used where the non-organic components do not exceed 30\% of the total volume in the product.
} 


\section{Verification and Certification}

The role of a certification body is to confirm that, after appropriate inspection, the products and the processes by which they were produced adhere to a specific organic standard. The applicable national standard serves as the baseline that a product must meet in order to enter markets as organic and the private standards of accredited certifiers will always meet the minimum requirement of the importing country. However, certification organizations - most of which are private - may have their own requirements that are more demanding. Since these may have developed a certain level of buyer trust over the years they can be a de facto requirement for sales in certain markets. This is particularly true in northern Europe where the first mover certification organizations still enjoy market dominance. As of 2005, there are approximately 420 organizations certifying organic products around the world though the lion's share of the business is certified by a handful of major concerns.

Once certified, organic products are marketed usually carrying an approved organic certification label. Even within the EU there are considerable internal trade barriers for organics. Problems emerge when trying to sell a product in different markets whose distinct requirements make recertification necessary. Since there are discrepancies within and between public regulations or private standards and the actual certifications, or even in governments' accreditation requirements for certification bodies, a number of problems arise that increase the cost of organics and not surprisingly help the certification industry to thrive in fragmented and less than transparent market conditions.

Certification fees are high for small farmers in many developing countries and in some cases can run into the thousands of dollars. For example, international certification for an average farm in China cost from US $\$ 1,446$ to US $\$ 2,410$ in 2004. Costs tend to be somewhat lower for domestic certification where this exists, but given typically limited domestic premiums in developing countries this too is still expensive for small farmers. In recent years a number of domestically based certification agencies, often affiliated with or owned by prominent international certifiers, have emerged in developing countries to reduce costs.

One popular alternative for lowering costs is group certification whereby a certifier works with a farmer group to help ensure internal compliance among the group using Internal Control Systems (ICS) and to facilitate inspection wherein the certifier directly inspects only a percentage of the farmers randomly to verify the integrity of the ICS. By managing their own ICS, farmers not only minimize compliance costs but also improve their own internal management structure. ICS that have been developed as part of the certification structure for cooperatives and producer groups have been shown to reduce certification costs to a minimum level; in some cases to as low as a few dollars per farmer. With the support of IFOAM, smallholder group certification procedures have been officially sanctioned by the EU for developing countries only and Japan allows it both domestically and for imports. The US has not officially sanctioned the process although such products can enter these markets. Participatory Guarantee Systems (PGS) refer to local peer assurance systems for domestic markets. These are particularly useful for small producers who are not engaged in exports and are being established not only in developing countries like Brazil and India but also in the US and Europe. Notably, these PGS are not recognized in any regulation other than the Brazilian, so farmers in Europe or 
the US that participate in those systems may say that it is organically grown but can not legally market their products as organic.

\section{Constraints for Organics in Developing Countries}

Organics provide a unique set of market opportunities. Yet, small and medium organic farmers in developing countries face many of the same challenges of their conventional counterparts such as the lack of access to extension services, inputs, and financing. The fundamentally unique constraints for organic development are:

1. Organic production is a learning process that requires adequate time to be fully adopted and transitions can therefore take several years to achieve their full potential.

2. Few if any of the institutions and incentives that exist for conventional agriculture (i.e. research centers, input subsidies, trained extensionists, etc.) are available for organics.

3. Transaction costs for certifying products can be high and a distinct barrier for poorer producers. Standards for different markets are diverse and not harmonized thereby increasing certification costs and also making compliance more difficult.

4. Local market demand is modest with low consumer awareness. The few established distribution or sales outlets are often not part of the mainstream.

Local knowledge and transition periods

Without adequate knowledge of organic cultivation techniques or the support of practical research and extension services, many farmers will struggle especially in the first years of transition. There is evidence of yield improvement for traditional farmers who take up organics but for intensive and high input farmers, the transition to organics can often mean either a temporary or a permanent reduction in yields. Such a shift must be carefully evaluated for its costs and benefits. Since some organic methods are site-specific and condition-sensitive, they can be intrinsically more difficult for extension agents to convey. Therefore organic agriculture must rely more on local and indigenous knowledge as well as support from development agencies and NGOs.

In this sense organics lend themselves to community-oriented and farmer-to-farmer methods of knowledge transmission. This approach fits the reality that in many remote areas government support services for any kind of agriculture are inadequate for farmers. It is particularly true of extension where the training of extension technicians and their ability to reach out are both minimal. None of the 14 projects studied in IFAD's recent thematic evaluation of “Organic Agriculture and Poverty Reduction in Asia” found that public extension services provided adequate training benefits.

Most extension agents have no experience in organic methods and in some areas they are increasingly trained by, and affiliated with, agrochemical distributors that are replacing governments and research institutions as not necessarily impartial sources of information for 
farmers. For intensive farming operations that monocrop and are mechanized to handle only that style of production, adapting to crop rotations and intercropping can be difficult. Since production technology is vital in organics, there is a critical role for NGOs and development agencies to help farmers bridge this missing knowledge link.

\section{Institutions and incentives}

Conventional agriculture has often developed various support mechanisms in the form of dedicated institutions such as research agencies and extension systems and also incentives such as input subsidies and price supports. Despite the credible case for the public goods aspects of organic production, few if any such benefits have emerged for the organic sector in most developing nations. In some cases local institutional support systems such as NGOs may have a greater affinity for organic methods and can provide some of the missing know-how to producers. NGOs, while very useful, have their limitations. They are not necessarily well trained or up to date on production technology such as pest control methods for different crops. In terms of marketing, they may have an advantage over a farmer i.e. language or familiarity with urbanbased buyers, but they often lack the marketing skills required for international sales and transactions.

\section{Transaction costs}

In some cases, standards can create new barriers to entry that threaten the poorest producers with additional production costs and new demands. Developing country producers are typically not active participants in the setting of standards and most have been developed in northern markets. However, through international umbrella organizations such as IFOAM, organic producers have some voice in this area. The process of certification can be a costly and sometimes lengthy learning exercise. For larger wine producers in Chile organic certification (including the learning processes) represented about $5 \%$ of their operating costs whereas for small wine producers (10 ha or less) the costs of getting certified represented up to $25 \%$ of their operating expenses (cited in UNCTAD 2005 p.51). The hidden indirect costs of training, marketing and coordination can be costly and difficult to manage for farmers and their organizations. Most are unable to estimate what these might be even though it appears likely that such indirect costs are even greater than direct costs according to the hypothesis of a new multistakeholder initiative to measure the complete costs and benefits of sustainability initiatives such as organics. $^{18}$

Farmers, firms, and consumers can clearly benefit as certification agencies and inspectors establish an increasing presence in developing countries and costs are reduced through group certifications. For farmers, developing and managing their own Internal Control Systems (ICS) is an effective way to both minimize compliance costs and improve the responsibility and skills of the farmer association's management structure. By allowing farmer's groups to share in the costs and management of their certification, they become better prepared to manage the plethora of other standards that are increasingly mandated for global trade.

\footnotetext{
${ }^{18}$ Costs of Sustainable Agriculture (COSA) project based in The International Institute for Sustainable Development
} 
Organic markets for a number of products are still shallow in terms of dedicated trans-national distribution channels with a very limited number of sizeable brokers and traders. In practice a developing country producer or exporter is very dependent on an importer based in the target market. This is certainly the case in the EU where most developing country products enter via a derogation rule whereby the importers are often required to apply for an import license that is issued directly to the importer and constrains the exporter to use that importer's license or incur the additional cost and difficulty to solicit other buyers in the EU. When alternatives are unavailable in the organic markets, products are sold through conventional channels and while being certified may make such products more attractive to some buyers, they will rarely receive a price premium.

While the US and Japanese regulations have introduced organic labels that are generally recognized and respected by consumers, the EU, though it has its own label, still has a proliferation of private labels and logos of certifying agencies that consumers have learned to be familiar with and this makes it more difficult for products to successfully cross EU borders without additional costs of certification to the dominant label in each market.

\section{Local markets}

Developing locally oriented initiatives may not only provide benefits for domestic consumers but can also provide a stepping stone for subsequently approaching export markets. Local market demand is typically modest in the early stages of development as consumers build up an awareness of organics. There is evidence that government support can quickly impact this area but through policy support and information rather than in the form of stringent regulations.

In OECD countries regulations have typically been stimulated by concerns for their domestic markets whereas most developing countries regulate primarily to facilitate exports. In fact, there seems to be no correlation between regulations and the facilitation of either exports or a domestic market. ${ }^{19}$ Regulations may certainly provide legitimacy and visibility but they can also serve to hinder development. Despite many countries with credible national regulations, there are few equivalency agreements as a result of them and nearly all of the products imported into the US or the EU have to be certified according to US or EU regulations. In many cases having qualified and low-cost certification agencies, coupled with marketing support (i.e. information, trade fairs, etc.) is a more efficient way to use government resources. For domestic markets, having a common and clear organic standard (voluntary or otherwise) is more important than regulations, particularly at the early stages. It should be developed consensually with all of the key stakeholders and be reasonably simple for producers to apply and certifiers to verify. If the standard is built on an international model i.e. IFOAM or Codex with local adaptation it will also facilitate import trade and export development.

China developed substantial markets quickly by investing in organic certification and support systems for farmers and businesses initially through its Environmental Protection Agency and

\footnotetext{
${ }^{19}$ Prior to 2002, when US regulations were implemented, the domestic market for organic products had already grown to a very respectable US\$ 7 billion and was experiencing faster growth rates than those after 2003. The experience with EU regulation is similar.
} 
provincial or local governments. In India some state governments have taken the lead. One has invested in direct state-wide NGO support for the local production and distribution of organic foods.

Domestic markets often begin when individual organic farmers emerge in local markets along with Box Schemes, Teikei ${ }^{20}$, or Community Supported Agriculture that are a production agreement between a farmer and a group of consumers. Most are not certified and rely on their reputation. While in earlier stages the costs and bureaucracy of certification or regulation will likely stifle domestic market development and basic regulations (i.e. truthful labeling laws) are likely to be sufficient. Then as domestic demand develops specialized shops are usually the first to introduce organic products at the formal retail level. These few initial distribution outlets have attractive margins and are not part of the mainstream. At this stage it becomes more difficult to ensure the integrity of supply and certification of some sort becomes relevant. As the market grows, larger distributors with economies of scale strengthen and then help to stabilize the demand. In some cases, larger scale operators step in early and create a significant first-mover advantage. One of the world's most successful supermarket chains (measured in sales per square foot), the US-based Whole Foods Markets, is an example of this. At these later stages of domestic market development, the requirements resemble those of export markets including the need for certification and credible accreditation.

Public procurement is considerable in many countries and, as France and Austria have already demonstrated, providing school lunches and adapting procurement in government offices, schools, hospitals, etc. are ways to develop the domestic organic sector at low cost while also providing a public community benefit as local farmers can often supply local institutions.

\section{Key Policy \& Investment Issues and Recommendations}

In many developing countries, governments have often adopted a position of benign neglect toward organic systems and typically perceived them as a marginal agricultural segment. Misperceptions still exist and some policymakers consider organics to be primitive agriculture rather than a sophisticated bio-systemic approach to rural development. However, two independent evaluations for IFAD measuring smaller farmers in Asia and Latin America suggest that many organic farming operations are either as successful or often more so - when measured in terms of higher income and reduced risks - than their neighbors that utilize traditional-rustic or even conventional methods.

Despite these positive aspects some caution is warranted. As with any standard, it will not apply to all farmers or to all situations. As with any standard, there are failures. Two sorts of assessments can be particularly important for determining the practicality of implementing market-oriented organics. First is a cost-benefit analysis to evaluate the expected differences

\footnotetext{
${ }^{20}$ Teikei is one of the original systems of modern community-supported agriculture now used by millions of Japanese consumers to purchase food directly from farmers. It is closely associated with small-scale, local, organic farming.
} 
between an organic approach and current cropping system in order to properly assess the set of impacts as a result of the change of cultural practices (i.e. labor, resource management, potential reduction in yields) as well as the direct and indirect costs of certification and meeting requirements. The other vital assessment is a feasibility study of existing market opportunities, costs, and risks for the products and farmers being considered. This should include a sensitivity analysis for variations in the organic premiums to ensure that the project's success is not completely dependent on price premiums that are likely to change.

Other important lessons have emerged from organic development projects around the world. Attention to six fundamental areas can facilitate organics as a viable choice that farmers can select.

\section{Institutions}

Perhaps the single most important factor for successful organic adoption is the availability of reliable institutional support systems (local and national) that can initially help make available the many necessary components of a successful transition that farmers find difficult to access (see Table 3). At the national level especially in the government \& public sector it is important to build capacity and investment in organic research \& extension services. These can disseminate international best practices as well as domestic adaptation of production expertise and post-harvest technology. Policy level issues are equally important and addressed below in the Public Investment section. Private institutions including NGOs and trade or farmer associations serve a useful role if they can bridge the gap between farmers and international demand to convey up to date market information and standards developments as well as provide input to standards at the international level in various fora such as IFOAM.

At the local level, public and private institutions are essential in order to provide practical knowhow and hands-on experience in production and post-harvest technology: an area that farmers have identified as one of the most critical components for them to convert to organic. The table below shows the results of farmer surveys in case studies for the IFAD evaluation of organics in Asia and has some similarities to findings in an earlier IFAD report on Latin America.

\section{Table 3.}

\begin{tabular}{|l|c|}
\hline \multicolumn{2}{|c|}{ Farmer Ranking of Intervention Priorities to Facilitate Conversion } \\
(1 is most desired and 5 is least desired)
\end{tabular}

Source: Giovannucci $2005 a$. 
Local efforts can strengthen a central public-private body or NGO as an institutional focal point for the provision of: farmer-friendly knowledge bases; information dissemination; and even extension services that can be facilitated on topics such as seeds and other inputs, pest \& disease control, cultivation standards, and quality control methods. Such a focal point in the area can even offer some marketing support to farmers and local enterprises (organic input suppliers, traders, etc.). Such institutional efforts are particularly important when developing farmers who are 'organic by default' (a somewhat misleading term for farmers that do not use agrochemicals since organic methods involve more than the absence of synthetic chemicals). Certifying such farmers without developing the necessary cultivation and marketing skills may provide a shortterm benefit —assuming they have a buyer — but leaves them without many of the necessary requirements for long-term success.

\section{Farmer organizations}

Farmer organizations are pivotal for any sound organic strategy. They are a vital conduit of information necessary for farmers to succeed in organic transitions. The learning process for conversion involves prolonged challenges in meeting standards, certification, and marketing needs. In order to achieve competitiveness and maintain continuity at the market level farmer organizations will need to strengthen their internal management capacity and their ability to represent their constituency. It is important to strengthen a farmer's knowledge and collective bargaining position through such organizations in order for them to effectively negotiate with a larger private sector partner (buyer, contract farm, outgrower manager). Since many associations and NGOs lack the business skills to negotiate the various aspects of marketing, they may need help to organize an apex body or a network of organizations that can then establish a business unit and be fortified with professional support and training in order to develop scale economies.

\section{Public-private alliances \& small farmers}

It is not necessary to turn a farmer into a trader. The private sector can readily fill that role. To integrate with private sector requirements, forms of contract farming are very popular in organics and can provide mutually beneficial partnerships between farmers and firms; yet caution is warranted since a firm's goals tend to vary from a farmer's best interest. The relationship works best when there is a dynamic balance between farmer and trader or processor. Without farmer ownership of at least part of the organic certificate and business venture (if any) their equity in contract farming systems is severely diminished.

\section{Strategy}

As a sector grows, its development, public investments, and policy support ought to be at least initially coordinated with a credible and representative body in compliance with a master strategy plan that is developed and approved by most stakeholders. Harmonizing the efforts of various stakeholders will thus help to improve learning, build synergies, and better use limited resources. Experience indicates that it is best to first focus on areas where organics align with current government objectives in areas such as agriculture, environment, and food security.

One development strategy considered in a number of nations is the development of mandatory organic regulations with the primary intention to protect the organic sector at the early stages of 
its development. Some notable organic experts such as former IFOAM president Gunnar Rundgren feel that in many cases strong government regulation can do more harm than good and can not only be detrimental to poorer producers by exacerbating the demands placed on them but also possibly hinder the sector's overall development. Diverting scarce resources toward this may not be the best initial course of action. Often a set of clear guidelines and enforceable truth-in-labeling laws are sufficient to first stimulate local organics in new markets. Resources can better be directed toward having a clear and coherent organic standard, building institutions, facilitating promotion, and disseminating knowledge to support farm conversions.

Another strategy explores the idea of concentrating initial efforts on specific regions that may be easier for the organic certification process (strong farmer interest, away from polluting industrial areas, little reliance on synthetic input use, etc.). This approach maintains that interest in intensive conventional agricultural development will likely not be feasible in all areas and that therefore organics can present a different menu of options for remote areas that may be otherwise difficult to develop as intensive production areas. While this is probably true, and could be one of the viable approaches, it will be important to not relegate organics only to difficult areas where it is at a great disadvantage in terms of infrastructure, extension, and market access. Doing so would certainly prevent many farmers from seeing whether, in a direct comparison with conventional or rustic methods, the costs and benefits of organics make sense for them.

\section{Public Investment}

Organics can provide "public goods" in the form of resource conservation, biodiversity, soil and water management, etc. These benefits and the efforts required to meet and monitor the elevated standards that provide them may not be adequately rewarded by the market alone. Sound public policy cannot be built on the expectation of market price premiums. So, as a starting point, it would be reasonable to eliminate biases in public expenditures that put organics at a disadvantage and consider:

- Revolving fund for farmers to access initial financing required for certification and initial investments i.e. vermicomposting, biopesticide production, or livestock that are useful in integrated systems for manure, food, traction, etc.

- Integrate organics into public procurement (in Europe some schools, hospitals, and governments specifically require at least a certain percentage of organic foods if these are available) to stimulate both a base market demand and improve the public information and consumer exposure to organics. There can be close synergies between small farmers and the rural schools or hospitals in their regions.

- Government's incentives or tax exemptions for conventional inputs are inherently biased against organic methods. Equivalent support can be applied to organics or similar benefits could be channeled like extension services and support for biological pest controls. Limited-time tax exemption mechanisms especially when applied to value adding activities such as processed organic products can stimulate organic development and motivate supply chain investments.

- Incentives in the form of limited subsidies for initial certification and transition phases. 
- Equitable development \& consumer protection will require labeling rules similar to those of the US, Japan, and the EU that protect the use of terms like: “organic”, “eco”, or "bio". Similarly, the development of a common national identification label can facilitate market development and give consumers a clear choice.

Governments can also invest more directly to surmount important constraints. For example, the Brazilian Export Promotion Agency (APEX) in 2005 announced the launch of its Brazil Organics Project to specifically promote and support the exportation of organic products. In India's Karnataka the government provided start-up funding to vetted NGOs in 26 districts for a broad scale farmer conversion program. Tunisia provides excellent organic certification compensation to its interested farmers.

\section{Conclusions}

The situation for the development of organic agriculture is promising but also challenging.

- As a standard it fulfills many of both the public and private requirements of modern trade i.e. good agricultural practices, traceability, low or zero residues.

- As a business model, nearly everyone involved in the production, processing, and trade of organic produce earns more money.

- As a development model an organic production system has intrinsic characteristics that can impact nutrition security, be suitable to smaller under-capitalized farmers, and help them to better manage agronomic risk. Organic farming is primarily knowledge intensive, whereas conventional farming is more capital and chemical intensive.

- Moreover, some of the related externalities, including resource conservation and soil fertility, may be even more valuable than the economics in the long run and ought to be a primary focus of organic development strategies.

Nevertheless, organics are not a perfect solution.

- The potential benefits are not always immediate and may require several years of commitment to see tangible results. Organics are not only concerned with the reduced use of agrochemicals, as a systemic approach, they require long term commitment to learning and working within the sustainable boundaries of a biological system.

- Conventional farmers may experience significant yield declines, especially in the initial transition period.

- The site-specific nature of organics implies innovation as producers must rely on local ideas, resources, and management blended with available scientific insight. It can therefore be challenging to organic farmers whose products must meet the same performance requirements as conventional ones. 
- Successfully implementing organic programs requires an active farmer learning-support system to address both the production and the post harvest technical requirements of organics.

- Organic regulations can become a barrier to entry and in local markets simpler alternative and localized credence systems can be adequate for exchange where farmers and consumers, or a credible intermediary, are familiar with each other.

- Care must be taken in the promulgation of organic certification and commercialization since these require parallel efforts to enhance farmer knowledge and organization. Not everyone needs international certification and it can be expensive when direct and indirect costs are calculated.

Organics have emerged from being part of a small niche. The future direction clearly involves participation in larger and more mainstream markets and increasing competition based on quality attributes and price. For market-oriented farmers, growth will increasingly mean having to meet the tough performance demands of competitive distribution channels particularly those dominated by supermarket chains. Global trade does not thrive on confusion and inefficiency and the global system of organic regulations and verification methods is far from perfect. These systems are not harmonized and vary across countries and even between certifiers thereby creating a considerable burden for producers and higher costs for consumers. Besides preventing their own growth such disjointed systems also create incentives for other agricultural “certifications" with claims to sustainability.

Organics do not provide the answer; however, they can certainly be a valuable part of wider efforts to promote the sustainability and productivity of agri-systems. While the international trade dimensions of organic standards are certainly valuable they may not be the most important aspects. There appear to be a number of less tangible benefits ranging from farm level food security to community-level health to regional environmental benefits. There is evidence that organic agriculture because of its higher value, environmental friendliness, and greater remunerative use of rural labor can help reduce poverty and even create new business opportunities. Organics can offer a unique combination of environmental, health, and commercial benefits in one systemic package. 


\section{References and Resources}

Altieri, Miguel and C.I. Nicholls. 1999. Biodiversity, ecosystem function and insect pest management in agricultural systems. In W.W. Collins and C.O. Qualset (Eds) Biodiversity in Agroecosystems. CRC Press, Boca Raton, FL.

Barling, D. 2003. Impact of international policies and agreements on the development of organic farming. In Groenewegen, P., den Hond, F. \& van Straalen, N. (Eds) Pesticides: Problems, Improvements, Alternatives. Oxford: Blackwell Science

Bartram, Hannah and Allan Perkins. 2003. The Biodiversity Benefits of Organic Farming. Published as a monograph on the proceedings of The OECD Workshop on Organic Agriculture; September 2002. Paris: OECD

Bowen, Diane, Joy Michaud, Els Wynen (Eds). 2004. Harmonization and Equivalence in Organic Agriculture Volume 1: Background papers of the International Task Force on Harmonization and Equivalence in Organic Agriculture Bonn: UNCTAD, FAO and IFOAM

Clark, E., D. Pimentel, and F. Troeh. 1992. Soil Erosion. In Charles Kidd \& David Pimentel (Eds) Agroforestry for Development. Academic Press

Crucefix, David. Forthcoming 2006. Experience of Equivalence and Recognition Mechanisms in the Regulation of Organic Agriculture. IFOAM-FAO-UNCTAD.

Drinkwater, L., P. Wagoner, and M. Sarrantonio. 1998. Nature. Volt 262 p. 396.

2002. EC Regulation on "Organic Farming", A Legal and Agro-Ecological Commentary on the EC Council Regulation (EEC) No 2092/91. GTZ Program Office for Social and Ecological Standards Sector. Project Organic Agriculture www.gtz.de/organic-agriculture

FAO. 2002. Organic agriculture, environment and food security. N. Scialabba \& C. Hattam (Eds) Published as monograph Environment and Natural Resources Series. N4. Rome: FAO

Geier, Bernward and Christina Westermayer (Eds). 2003. The Organic Guarantee System: The need and strategy for harmonisation and equivalence. Bonn: IFOAM

Gibbon, Peter. 2005. Decoding Organic Standard-Setting and Regulation In Europe. Vienna: UNIDO

Giovannucci, Daniele. 2005a. Organic Agriculture and Poverty Reduction in Asia. International Fund for Agricultural Development: Rome

Giovannucci, Daniele and Stefano Ponte. 2005b. The Collective Formulation and Effectiveness of Public \& Private Sustainability Standards: In special issue of Food Policy Journal, "Private Agri-food Standards: Implications for Food Policy and the Agri-food Systems”. 
Giovannucci, Daniele. 2003. Emerging Issues in the Marketing and Trade of Organic Products. Published as a monograph on the proceedings of The OECD Workshop on Organic Agriculture; September 2002. Paris: OECD

Hamm, Ulrich, F. Gronefeld, \& D. Halpin. 2002. Analysis of the European Market for Organic Food. Organic Marketing Initiative \& Rural Development, Vol. 1 .School of Management \& Business, University of Wales Aberystwyth.

Huber, B. 2005. Organic Certification Worldwide. Frick, Switzerland: FiBL

International Strategic Marketing Group. 2005. U.S. Market Profile for Organic Food Products. Washington: USDA

Kilcher, Lukas, Beate Huber, Otto Schmid. 2006. Standards and Certification. In Willer, Helga \& Minou Yussefi (Eds). The World of Organic Agriculture: Statistics and Emerging Trends. Bonn: IFOAM

Kortbech-Olesen, Rudy. 2000. Export Opportunities of Organic Food from Developing Countries. Presentation made at WorldOrganics 2000. London

Lampkin, Nicholas, C. Foster, S. Padel, and P. Midmore. 1999. The Policy and Regulatory Environment for Organic Farming in Europe. In Organic Farming in Europe: Economics and Policy. Vol. 2, Stuttgart-Hohenheim University..

Lotter, Don, Rita Seidel, and William Liebhardt. 2003. The Performance of Organic and Conventional Cropping Systems in an Extreme Climate Year. American Journal of Alternative Agriculture, 18(3) pp. 146-154 (9).

Mäder, Paul, Andreas Fließbach, David Dubois, Lucie Gunst, Padruot Fried, and Urs Niggli. 2002. Soil Fertility and Biodiversity in Organic Farming. Science Vol. 296, Issue 5573.

Parrott, Nicholas. 2004. Sound Depths: the Seen and Unseen Dimensions of Organic Farming in the South. Paper for DARCOF Copenhagen 2004 Workshop on Organic Farming in a Global Perspective: Globalisation, Sustainable Development and Ecological Justice.

Pimentel, David. 1995. Economic Growth, Carrying Capacity, and the Environment. Science 268:520-21.

Pretty, J. N., A. D. Noble, D. Bossio, J. Dixon, R. E. Hine, F. W. T. Penning de Vries, and J. I. L. Morison. Resource-Conserving Agriculture Increases Yields in Developing Countries in Environmental Science and Technology 2005

John Reganold, Jerry Glover, Preston Andrews, Herbert Hinman. Sustainability of Three Apple Production Systems. Published in Nature Vol 410 April 2001 
Rundgren, Gunnar. 2005. Certified Organic: Reducing Barriers to Developing-Country Exports of Conformity Assessment Services. Paris: OECD

Rundgren, Gunnar. 2002 Organic Agriculture and Food Security. Bonn: IFOAM

Sahota, Amarjit. 2006. Overview of the Global Market for Organic Food \& Drink. In Willer, Helga \& Minou Yussefi (Eds). The World of Organic Agriculture: Statistics and Emerging Trends. Bonn: IFOAM

Scialabba, Nadia, C. Grandi and C. Henatsch. 2002. Organic Agriculture and Genetic Resources for Food and Agriculture. In Biodiversity and the Ecosystem Approach in Agriculture Forestry and Fisheries Proceedings of satellite event to the 9th Regular Session of the Commission on Genetic Resources for Food and Agriculture. Rome: FAO Inter-Departmental Working Group on Biological Diversity for Food and Agriculture.

Stolton, Sue (Ed). 2005. Organic Agriculture for Biodiversity: Current contributions and future possibilities Bonn: IFOAM

The Organic Standard (various). Höje, Sweden: Grolink AB (available through www.organicstandard.com)

Twarog, Sophia. 2006. Organic agriculture: a trade and sustainable development opportunity for developing countries. In the Trade and Environment Review. Geneva: UNCTAD

UNCTAD Trade, Environment and Development Branch. 2006. Trade and Environment Review. Geneva

van der Vossen, H. 2004. Organic Coffee Production: Myth or Reality - a Review. In the proceedings of 20th ASIC International Conference on Coffee Science September 2005: Montpellier, France

Willer, Helga \& Minou Yussefi (Eds). 2006 forthcoming. The World of Organic Agriculture: Statistics and Emerging Trends. Bonn: IFOAM

World Conservation Union (IUCN) and Future Harvest. 2001. Common Ground, Common Future: How Ecoagriculture Can Help Feed the World and Save Wild Biodiversity.

Worldwatch Institute. 2000. State of the World 2000. Washington, D.C.: Worldwatch Institute. Available at http://www.worldwatch.org/pubs/sow/2000/

\section{Websites:}

International Federation of Organic Agriculture Movements http://www.ifoam.org/

IFOAM offers a variety of relevant publications including:

Smallholder Group Certification Manuals. 
The Guide to the Development of Certification Documents (in Spanish and English) The International Organic Inspection Manual (in Spanish, French and English) Building Trust In Organics: A guide to setting up organic certification programs The Training Manual for Organic Agriculture in the Tropics.

Food and Agriculture Organization FAO, Website "Organic Farming at FAO” http://www.fao.org/organicag/

European Commission, DG Agri, Organic Farming Website

http://europa.eu.int/comm/agriculture/qual/organic/index_en.htm

Foundation Ecology and Agriculture (SOEL)

http://www.soel.de/english/index.html

International Accreditation Forum

www.iaf.nu

International Organic Accreditation Service

www.ioas.org

Research Institute of Organic Agriculture (FiBL)

http://www.fibl.org/english/index.php

FiBL Organic Europe Homepage

http://www.organic-europe.net/

Unites States Dept. of Agriculture National Organic Program

www.ams.usda.gov/nop 